Lenguaje, sociedad y escuela 


\title{
Enunciación
}

\section{Aproximación sociolingüística a las fórmulas de tratamiento nominales en el contexto comunicativo juvenil}

\author{
Sociolinguistic approach to nominal treatment forms \\ in the youthful communicative context
}

\author{
Andrés Mahecha Ovalle*
}

\section{Resumen}

Este artículo describe las fórmulas de tratamiento nominales empleadas por los jóvenes con edades comprendidas entre 13 y 17 años residentes en la localidad de Kennedy (Bogotá D. C.) en tres ámbitos comunicativos: amistad, familiar, social. La recolección de datos se realizó a través de dos instrumentos: la grabación espontánea y del cuestionario. Para la selección de los informantes, se empleó la técnica de muestreo selectivo efecto bola de nieve. El corpus se constituyó de 30 grabaciones espontáneas y de los datos recolectados de la aplicación de 70 cuestionarios. Los resultados demuestran que las comunidades juveniles codifican en las fórmulas de tratamientos nominales aspectos como la distancia social, las relaciones de poder, la cortesía lingüística y la resemantización de ítems léxicos. Asimismo, se evidencia una variación en el tratamiento de acuerdo con el contexto y los participantes que intervengan en el acto comunicativo, lo cual contribuye al cambio o adaptación del comportamiento lingüístico del joven. Los hallazgos permiten inferir que el tratamiento nominal es una estrategia conversacional del joven en sus interacciones cotidianas.

Palabras clave: habla juvenil, formas de tratamiento nominales, comunidad de habla, ámbitos comunicativos, sociolingüística interaccional.

\begin{abstract}
This paper describes the nominal treatment forms used by young people aged between 13 and 17 who live in Bogota D.C. in three communicative areas: friendship, familiar and social. Data collection it is done through two instruments: spontaneous recording and questionnaire. For the selection of informants, the selective snowball sampling technique was used. The corpus was made up of 30 spontaneous recordings and data collected from the application of 70 questionnaires. The results obtained show that youth communities code aspects such as social distance, power relations, linguistic courtesy and resemantization of lexical items in the nominal treatment forms. Likewise, there is evidence of a variation in treatment according to the context and the participants involved in the communicative act, which contributes to the change or adaptation of the young person's linguistic behavior. The findings allow us to infer that nominal treatment is a conversational strategy of young people in their daily in interactions.
\end{abstract}

Keywords: youth speech, nominal treatment forms, speech community, communicative context, interactional sociolinguistics.

Magíster en Lingüística, Seminario Andrés Bello, Instituto Caro y Cuervo. Especialista en Procesos Lecto-Escriturales, Corporación Universitaria Minuto de Dios y Licenciado en Educación Básica con énfasis en Humanidades e Idiomas por la Universidad Libre. Correo electrónico: andres320_@hotmail.com

Cómo citar: Mahecha Ovalle, A. (2020). Aproximación sociolingüística a las fórmulas de tratamiento nominales en el contexto comunicativo juvenil. Enunciación, 25(2), 272-291. https://doi.org/10.14483/22486798.16187 Artículo recibido: 22 de abril de 2020; aprobado: 19 de junio de 2020 


\section{Introducción}

Las fórmulas de tratamiento establecen un procedimiento empleado para determinar el contacto con el interlocutor. Estas fundamentan un entramado de relaciones entre hablante y oyente, las cuales están mediadas por factores sociales, como: edad, sexo, estrato social, distancia social, relaciones de poder y el contexto comunicativo. Estas variables sociales inciden sustancialmente en la elección y uso por parte de los hablantes. De acuerdo con Rebollo (2005), "la manera como nos referimos al interlocutor fundamenta nuestras relaciones y nos localiza en una compleja red de imágenes sociales, que se pueden negociar en la interacción con los demás" (p. 35). En este sentido, las fórmulas de tratamiento nominales (FTN) presentan variaciones según los individuos involucrados en la comunicación y determinan aspectos sociales en la comunicación. Por ello, estas tienen codificado el grado de confianza, respeto, elementos de cortesía verbal, relaciones jerárquicas ${ }^{1}$. De modo que las FTN se constituyen en factores de deixis social (Blas, 2004), la cual se determina a través de las interacciones comunicativas entre los miembros de una comunidad de habla.

Desde la perspectiva anterior, esta investigación se distancia sustancialmente de otros estudios sobre las FTN adelantados en el contexto nacional: Castellano (2008, 2011, 2012, 2014, 2017); Mestre (2011); García (2014); Gómez (2016); Arias, García y Ruiz (2016); Torres (2017); Arrieta y Avendaño (2018). Estos trabajos adoptan una perspectiva de indagación centrada en la cortesía lingüística, la caracterización morfológica, alternancia en el uso de pronombres y cómo las relaciones simétricas contribuyen a emplear una determinada serie

1 Dada la delgada línea entre la sociolingüística y pragmática, el presente trabajo asume estos factores desde la primera disciplina. Se hace énfasis en las variables extralingüísticas que configuran y delimitan el uso de las fórmulas de tratamiento nominales en los jóvenes. No obstante, como señala Medina (2010) es muy difícil hacer una demarcación entre sociolingüística y pragmática en relación con las nociones fundamentales de análisis. de FTN² ${ }^{2}$. Las investigaciones anteriores no adoptan un enfoque desde la sociolingüística interaccional para el estudio de las FTN. Por ello, el presente estudio se enfoca en analizarlas "como elementos que permiten codificar las relaciones interpersonales y sociales entre los hablantes" (Blas, 2004, p. 297). En otras palabras, los vocativos de tratamiento nominales se determinan y configuran desde las interrelaciones de los hablantes.

Según señala Baker (2010), el enfoque de la sociolingüística interaccional permite examinar cómo los hablantes crean, usan e interpretan el significado de las FTN desde la interacción social. Esta perspectiva de análisis del lenguaje se enfatiza en "que la lengua es un constituyente más de la realidad sociocultural, realidad que se construye, se mantiene y se transforma, en gran parte, por medio de las interacciones comunicativas en las que el uso del lenguaje desempeña un papel fundamental" (Berenguer, 2001, p. 47). En este aspecto, los tratamientos nominales juveniles se comprenden desde las conversaciones cotidianas en ámbitos comunicativos concretos. Este hecho permite la elección de las fórmulas y uso en contextos específicos en el marco de sus acontecimientos comunicativos en relación con los interlocutores que intervienen en la comunicación. Por ello, el empleo del tratamiento nominal juvenil es una práctica básicamente interaccional y sociocultural donde el hablante construye el significado de los vocativos de tratamiento desde un evento de habla particular. Desde este panorama, el estudio de las fórmulas nominales desde la sociolingüística interaccional es pertinente porque permite observar y estudiar al individuo en sus maneras de habla cotidianas en interacción con otros hablantes.

Desde la perspectiva previa, el estudio se centra en las FTN empleadas por algunos jóvenes

\footnotetext{
2 Sin embargo, se destacan los estudios realizados por Plazas (2013); Álvarez y Caraballo (2016); Miranda y Payares (2018), que se enfocan en el joven como individuo perteneciente a una comunidad de habla con unas características diferenciadoras de otros grupos etarios, perspectiva que sigue el presente estudio.
} 
residentes en la localidad de Kennedy (Bogotá D.C.) en sus ámbitos discursivos cotidianos: de amistad, familiar y social. Se seleccionó esta población debido a los diferentes contextos socioculturales donde los sujetos se hallan inmersos en su interacción comunicativa junto con las transformaciones sociales experimentadas por los adolescentes en la sociedad actual. Estas son los mass media, la informática y las redes sociales, que repercuten en el modo de hablar de los grupos humanos (Montero, 2011). En este sentido, las FTN están "codificadas en las lenguas a partir de las relaciones sociales e interpersonales que los hablantes mantienen entre sí" (Blas, 2004, p. 298). Es decir, se presenta una incidencia de los factores extralingüísticos y comunicativos en la elección de las fórmulas de tratamiento nominales.

La elección de informantes jóvenes con un rango de edad entre 13 y 17 años se sustenta en tres hechos fundamentales: el primero, la sensibilidad que desarrollan los hablantes durante esta edad temprana hacia la variación, según señala Halliday (2017). El segundo se basa en la construcción de la noción de joven, la cual va más allá de la edad. El concepto de juventud implica el estilo de vida, las nuevas maneras de interacción a través de plataformas sociales, su origen y sus condiciones de vida. Esta realidad sociocultural y sociolingüística permite formular un nuevo concepto de juventud, como afirma Rodríguez (2002). El tercer aspecto se apoya en la dinámica de innovación del lenguaje por parte del joven y "un fuerte sentimiento de grupo y utiliza en ocasiones formas lingüísticas propias" (Terrádez, 2001, p. 57). Desde estos motivos, se decide por la elección de informantes jóvenes con sus características descritas, las cuales se tienen en cuenta para este estudio.

De ahí que la investigación describe algunos de los cambios experimentados por las FTN empleadas por los jóvenes en el trato con sus amigos, familiares y con personas desconocidas. Los usos de las FTN evidencian las transformaciones ocurridas en los mecanismos lingüísticos involucrados en la interacción cotidiana en sus intercambios comunicativos entre sujetos de 13 a 17 años. Asimismo, los rasgos sociolingüísticos señalan que las FTN están insertas en la comunicación familiar y social por parte de los jóvenes. Su empleo se interpreta desde los factores extralingüísticos: la edad, el sexo, los mass media, la interacción en la red social, la cercanía, la solidaridad y el grado de poder. En consecuencia, la investigación analiza las FTN empleadas por jóvenes en ámbitos específicos en relación con las relaciones interpersonales y sociales entre los interlocutores.

\section{Metodología}

La investigación es cualitativa con un enfoque descriptivo, que se fundamenta en la perspectiva de la sociolingüística interaccional del estudio de las $\mathrm{FTN}^{3}$. Al respecto, Blas (2004) plantea la necesidad de abordar la variación lingüística desde el análisis de las interacciones verbales en la comunicación cotidiana. De manera similar, Calsamiglia y Tusón (2015) sostienen que "este enfoque se ha utilizado para analizar las interacciones que se producen en todos los ámbitos de la vida social en que quienes participan en los encuentros interactivos" (p. 21). Esta perspectiva de análisis se sustenta en las comunicaciones entre las relaciones de igualdad, desigualdad, pertenencia a grupos socioculturales o subculturas de los miembros de una comunidad.

Se seleccionaron 70 hablantes jóvenes de los cuales 31 correspondieron a hombres y 39 a mujeres. Estos tenían edades comprendidas entre los 13 y 17 años. Los sujetos objeto de estudio se dividieron en subgrupos: el primero, jóvenes entre 13 y 14 años; el segundo, individuos con 15 y 16 años y el tercero, quienes tenían 17 años. La elección de los informantes se llevó a cabo a través de la técnica de muestreo selectivo efecto

3 Este estudio se adelantó desde enero hasta octubre, 2018. 
bola de nieve, el cual "utiliza las redes sociales de los informantes para conseguir otros ('técnica del amigo del amigo') al consultarles a ellos mismos por otros conocidos que estuvieran dispuestos a ser encuestados" (Hernández y Almeida, 2005, p. 59). Este tipo de técnica permite obtener una muestra representativa y hace que participen hablantes que estén dispuestos a cooperar de manera activa. Es decir, la elección de los colaboradores es favorable al propósito que persigue la investigación.

La recolección de los datos se adelantó en dos fases: en la primera, se empleó la grabación espontánea, cuyo objetivo de acuerdo con Silva-Corvalán (2001) es "obtener una muestra de habla despreocupada, natural, lo más cercana posible al habla vernácula espontánea de la vida cotidiana" (p. 52). Se adoptó esta técnica debido a que se hace indispensable obtener datos fiables del habla cotidiana de los jóvenes objeto de estudio en sus contextos comunicativos cotidianos. La decisión previa se fundamenta en que "los datos más sistémicos y regulares para el análisis lingüístico se dan en el estilo informal y vernáculo" (Silva-Corvalán, 2001, p. 52). En la segunda, se utilizó el cuestionario, que se compuso por dos ejes: obtención de variables extralingüísticas -edad, sexo- y el contexto comunicativo -amistad, familiar, social-.

El corpus se constituye por 30 grabaciones de conversaciones espontáneas de los jóvenes con sus interlocutores en diferentes ámbitos comunicativos y, a su vez, de los datos arrojados por 70 cuestionarios aplicados a los informantes seleccionados. Así pues, para el análisis de los datos obtenidos, estos se clasificación por ámbitos: amistad, familiar y social. Se inserta la frecuencia de uso para establecer la representatividad de cada fórmula de tratamiento por ámbito comunicativo. Las FNT incluidas como ilustración provienen de la síntesis realizada de las grabaciones y el cuestionario por contextos comunicativos.

\section{Resultados}

\section{El tratamiento nominal en el ámbito de amistad}

En el ámbito de amistad se encuentran las fórmulas de tratamiento nominales con su respectiva frecuencia de uso, detalladas en la tabla 1. Esta se calcula por cada ámbito comunicativo.

Tabla 1. El tratamiento nominal en el ámbito de amistad

\begin{tabular}{lc}
\hline $\begin{array}{c}\text { Fórmula de tratamiento } \\
\text { nominal }\end{array}$ & $\begin{array}{c}\text { Frecuencia } \\
\text { de uso }(\mathbf{\%})\end{array}$ \\
\hline Nombre de pila & 34,62 \\
\hline Apellido & 10,01 \\
\hline Fórmulas amistosas & 24,09 \\
\hline Fórmula parce & 18,61 \\
\hline Fórmula sobrenombre & 8,05 \\
\hline Otras fórmulas & 4,09 \\
\hline
\end{tabular}

Fuente: elaboración propia.

\section{La fórmula nominal nombre de pila}

En primer lugar, los jóvenes emplean el vocativo de tratamiento nombre de pila para referirse a sus amigos en las distintas situaciones comunicativas ocurridas con sus interlocutores, con una frecuencia de uso del 34,62 \%. Este deíctico constituye el procedimiento más habitual entre los sujetos objeto de estudio para establecer contacto con el receptor. Lo anterior permite confirmar que el tratamiento entre compañeros se suele utilizar el nombre de pila (Álvarez, 2005). De manera general, esta fórmula tiene un valor apelativo en algunas situaciones. No obstante, esta realidad no se puede generalizar; puesto que en otras circunstancias no posee dicho valor. En este sentido, se afirma que esta forma es enunciada por los jóvenes para contactar con sus pares como vocativo denotativo. 
El nombre de pila se establece como la FTN más empleada en el ámbito de amistad. Este determina algunas maneras para interpelarse entre jóvenes. En otras palabras, se mantienen dos usos con finalidades específicas que se contrastan entre sí. Este aspecto se ilustra en la figura 1.

[Nombre + amistad]

[Nombre - amistad]

Figura 1. Uso del nombre de pila

Fuente: Carricaburo (1997).

El aspecto [nombre + amistad] establece un alto nivel de confianza y afecto entre los amigos. Este uso indica mayor grado de intimidad entre los interlocutores, el cual está conceptualizado como un aspecto de confianza, cercanía, afecto y solidaridad. Por tanto, la intimidad se configura en un rasgo de camaradería absoluta entre los miembros del grupo. Al mismo tiempo, se evidencia el establecimiento de una relación simétrica entre pares a través del uso del nombre de pila. Este hecho elimina la noción tradicional de poder ${ }^{4}$ entre emisor y receptor determinado en las interacciones comunicativas. De acuerdo con lo manifestado por algunos informantes ellos se denominan: "Por el nombre, ya que son mis amigos más cercanos y de confianza" (informante 43, 16 años, mujer); "por nombre o apellido a los de más confianza" (informante 41, 13 años, hombre); "siempre llamo a mis amigos por el nombre porque soy cercana a ellos" (informante 10, 17 años, mujer). Esto, además, permite confirmar que "el nombre de pila se utiliza para la intimidad o el afecto", como señala (Carricaburo, 1997).

El otro aspecto, [nombre - amistad], establece un grado menor de confianza y afecto en comparación con el primero, [nombre + amistad]. El

4 De acuerdo con Escandell (2014), el poder es entendido como la posesión y el control de los recursos considerados valiosos. El poder se convierte así en una marca de estatus social. uso del nombre de pila implica menos confianza, cercanía, afecto y solidaridad. Según los hablantes: "el nombre lo utilizo con quienes no tengo mucha confianza o empatía" (informante 20, 16 años, hombre); "para quienes no tengo cercanía empleo el nombre" (informante 40, 13 años, hombre); "con quienes no son mis amigos cercanos hago uso del nombre" (informante 30, 15 años, mujer); "a mis compañeros en general los llamo por el nombre" (informante 45, 14 años, mujer). De manera que este corresponde a una fórmula con un propósito netamente vocativo. Se emplea con quienes no se tiene un alto grado de intimidad. No obstante, no se puede hablar de desconocidos porque los interlocutores se reconocen mutuamente e interactúan de manera constante. Por tanto, en la utilización de [nombre - amistad] existe un grado mínimo de distancia social; mientras que en el uso de [nombre + amistad] esta se reduce a cero.

Desde lo expresado previamente, el nombre de pila se configura como la FTN más significativa en los intercambios comunicativos juveniles en el ámbito de amistad. Este se convierte en una estrategia conversacional de corte social, la cual implica el uso de una cortesía positiva para mitigar amenazas a la imagen del otro individuo. Se busca con su realización la mitigación de conflictos y, a su vez, se prioriza en las buenas relaciones con los interlocutores. De manera que en la interacción cotidiana juvenil predomina el nombre de pila tanto con quienes se tiene confianza como con aquellos hablantes donde esta es mínima. Si se apela a la noción de cortesía tradicional (Escandell, 1995) ${ }^{5}$, el empleo del nombre de pila evidencia una muestra de respeto $y$ reconocimiento del interlocutor desde el actuar comunicativo de los jóvenes.

En la fórmula nombre de pila se halla el apeIlido, que se utiliza con un índice de frecuencia

5 Tradicionalmente, la cortesía se había concebido como un conjunto de muestras de respeto o deferencia cuyo uso determina y exige la organización social, de acuerdo con Escandell (1995). 
del 10,01 \% en la comunicación cotidiana entre amigos. Este vocativo de tratamiento se establece como una manera formal de apelar al compañero en clase o en actividades grupales. Los informantes afirman: "siempre Ilamo a mis compañeros por su apellido cuando hago trabajos con ellos" (informante 9, 14 años, hombre); "me gusta el apellido, pues así se sabe a quién se llama" (informante 33, 16 años, hombre); "para mí el apellido es la mejor opción para comunicarme con mis amigos en actividades grupales" (informante 5, 13 años, mujer). Esta fórmula determina la cercanía entre los interlocutores. También, se produce con quienes se tiene un alto grado de confianza, amistad y solidaridad: "en mi caso llamo a mis amigos siempre por su primer apellido" (informante 15, 16 años, hombre); "para mí el primer apellido es la forma de comunicarme, pues lo considero más chévere que el nombre" (informante 55, 17 años, mujer). En este sentido, esta forma establece una cortesía positiva para el interlocutor. Lo anterior es corroborado por Álvarez (2005), "entre compañeros de estudio es habitual el uso del apellido" (p. 38). Desde esta perspectiva, el uso de esta forma se manifiesta mayormente con quienes se comparte una relación cercana.

Desde lo anterior, se observa que el nombre de pila representa el 44,63\% de frecuencia de uso en los acontecimientos comunicativos juveniles en el ámbito de amistad. Se evidencia que el antropónimo es empleado por los hablantes jóvenes sin distinciones de edad y sexo. La tendencia de uso del nombre de pila como la FTN preferida por los jóvenes es corroborada en las investigaciones realizadas en el ámbito hispánico. Entre los estudios se destacan los realizados por Alba de Diego y Sánchez (1980), en este trabajo prima este tratamiento con el $25 \%$; para Medina (1991), el nombre fue el más enunciado entre jóvenes con 29,3 \%, y Fontanella (1999) resaltó el nombre como la FTN preponderante en la comunidad juvenil.

\section{Fórmulas amistosas}

En el ámbito de amistad, las segundas FTN utilizadas son las formas amistosas (Carricaburo, 1997) con una frecuencia de 24,09 \%. En esta denominación se agruparon las FTN, que son empleadas para tratos cordiales entre amigos, compañeros de clase o con quienes se tiene una cercanía. Entre ellas están: bebé, blanco, bola, broder (sic), cariño, chico-a, compañero-a, enano, estúpido-a, flaco-a, flaquito-a, joven, mami, mani, men, mijo-a, morsh (sic), nené, ñero, oso-a, pa, pato, perro, roscón, tonto-a, weon. Las fórmulas previas son usadas porque permiten fortalecer los lazos de camaradería y mantener la unidad de grupo. Según lo expresado por los jóvenes informantes: "Empleo estas palabras men, mani, ñero, joven, enano, ya que manifiestan cariño hacia mis amigos" (informante 45, 14 años, mujer); "son palabras para denominar a mis compañeros, pero son palabras cariñosas: chico, cariño, estúpido, joven, pa" (informante 36, 15 años, hombre); "constantemente empleo bebé, broder, cariño y perro con mis parceros" (informante 38, 16 años, hombre). Estas declaraciones evidencian la familiaridad establecida entre los jóvenes desde la interacción con una FTN.

Algunas formas amistosas están fundamentadas en las características físicas e intelectuales de los interlocutores: blanco, bobo-a, enano, estúpido-a, flaco-a, flaquito-a, joven, negro-a, tonto-a. Este tratamiento se basa en aspectos corpóreos y etiquetas sociales del interlocutor involucrado en la comunicación, mas no es una manera despectiva de contactar al otro. Por el contrario, se centra en el afecto o la afectividad positiva. Los jóvenes hacen uso de estas fórmulas con el propósito de resaltar un atributo de la persona. Su empleo es frecuente porque es una manera de establecer contacto con el otro por medio del atributo del receptor, que adquiere una connotación positiva. Por tanto, los hablantes han realizado una resemantización de estos ítems léxicos para que no sean palabras insultantes. 
En este sentido, el grupo juvenil objeto de estudio no concibe las FTN basadas en características físicas o intelectuales como ofensivas ni peyorativas. Estas son desprovistas de toda connotación insultante o negativa para el receptor. Esto coincide con los hallazgos de Fontanella (1999) y Carricaburo (1997), quienes subrayan que las FTN empleadas por jóvenes en algunas comunidades de habla en el español peninsular y continental en la actualidad no poseen "designaciones peyorativas"

y "han perdido esa semántica peyorativa y parecen tener solo valor apelativo; así ocurre con [...] estúpido" (Carricaburo, 1997, p. 56). De este modo, se evidencia que la utilización de atributos corpóreos o cognitivos como tratamiento en las colectividades de habla juveniles son apelativos, que no tienen carga semántica peyorativa.

Cabe destacar otras formas amistosas empleadas por los jóvenes en sus actividades colectivas. Estas son: bolas, cariño, chicos, compañeros, güevones, mani, mor, morsh (sic), muchachos, nené, ñeros, oso, panas, patos, perros, roscón, tesoro, las cuales se enuncian sin distinción alguna en cuanto al sexo del hablante. Las anteriores FTN están orientadas a estrechar los lazos de camaradería presentes en los individuos, quienes comparten unos intereses comunes o prácticas socioculturales idénticas a sus amigos. De estas circunstancias, surge el hecho de que las formas nominales que denotan cariño se convierten en una rutina lingüística para establecer contacto entre hablantes con actividades en común. Estas configuran un determinado grado de empatía, aspecto que se traduce en pertenencia y aceptación de grupo.

\section{La fórmula "parce"}

El tratamiento parce se encuentra inscrito dentro de la denominación de fórmulas amistosas con una frecuencia de uso de 18,61\%. Esta denota un vínculo de afectividad entre amigos y compañeros en las interacciones cotidianas del grupo juvenil estudiado. De acuerdo con el corpus recolectado se aprecia: "casi siempre Ilamo a mis amigos como parce" (informante 2, 13 años, hombre); "empleo parce para amigos y compañeros" (informante 4, 17 años, mujer); "algunas veces uso parce para referirme a mis amigos" (informante 21, 14 años, hombre), y se asegura: "mis compañeros casi siempre lo usan conmigo" (informante 32, 15 años, hombre). Este hallazgo es manifestado por Arias, García y Ruiz (2016), quienes clasifican esta fórmula como una manera de expresar "amistad o compañerismo" dentro de "la afectividad positiva" (p. 67), en dos comunidades discursivas juveniles en la ciudad de Medellín, Colombia. Este hecho muestra una tendencia en los hablantes jóvenes a emplear la forma parce para manifestar relaciones de amistad y afecto positivo. Así mismo, lo anterior refuerza la aseveración de que los jóvenes tienden, en sus intercambios comunicativos, a disminuir la distancia social a través de este tratamiento.

\section{La fórmula sobrenombre con connotación de cercanía}

Dentro de los deícticos sociales se utilizan los sobrenombres en las comunicaciones cotidianas juveniles con una frecuencia de 8,05 \%. Según señalan los informantes 11, 31 y 70, los apodos se convierten en una manera para apelar a la segunda persona: "A mis amigos los Ilamo por apodos" (informante 11, 14 años, mujer); "utilizo apodos porque es como el alias que nos tenemos" (informante 31, 16 años, hombre); "algunas veces empleo apodos" (informante 70, 15 años, mujer). Los sobrenombres configuran una relación de cercanía entre los interlocutores; siempre y cuando estos pertenezcan al mismo grupo juvenil. En el conjunto de amigos su emisión denota características positivas para el receptor; mientras que, si quien recibe el apodo es un hablante no perteneciente al grupo, el apodo tendría un carácter peyorativo. Se destaca que en el primer uso existe una relación estrecha entre los interlocutores; en el segundo, este vínculo suele desaparecer. Por tanto, en el último la carga semántica del sobrenombre amenaza la imagen del interlocutor. 


\section{La fórmula [nombre + diminutivos]}

El [nombre + diminutivo] se convierte en la forma por excelencia para resaltar los lazos de compañerismo y camaradería entre los jóvenes. El nombre expresado en este rasgo morfológico simboliza el estrechamiento y cercanía de las relaciones sociales de los sujetos a través de su interacción comunicativa por medio de la fórmula nominal. El uso de [nombre + diminutivo] establecido por los hablantes en las situaciones comunicativas situadas en la amistad predomina con connotaciones positivas. Los jóvenes evidencian el cariño y el afecto con quienes se emplea dicha derivación apreciativa. Sin embargo, se hace presente el significado con un carácter negativo, mas este no llega a ser peyorativo.

\section{Otras fórmulas}

En otras fórmulas, se presentan los tratamientos como amor, marica, socio y [viejo + nombre], con una frecuencia baja de uso de 4,09\%. Al respecto de las formas previas, los informantes confirman: "a mis amigos los denomino como viejo más su nombre" (informante 21, 17 años, hombre); "en mi caso uso varias maneras: amor, marica y otros" (informantes 37, 15 años, mujer); "uso la forma marica" (informante 61, 13 años hombre); "uso la forma socio" (informante 51, 14 años, mujer). Estas fórmulas se orientan a establecer una comunicación de corte simétrica entre los interlocutores. Así pues, el joven en su red social emplea diversas FTN, en estas predominan aquellas orientadas a un trato de confianza y afecto. Dichas formas se enuncian como una estrategia conversacional para salvaguardar la imagen del interlocutor.

En el contexto amistoso, se presentan algunos términos usados como fórmulas que se resemantizan en el acontecimiento comunicativo y pierden su valor de insulto, el cual sí se hace presente en los hablantes adultos. Entre ellas se hallan bobo-a, estúpido, güevón, marica, negro-a, perro-a, roscón y tonto-a. Estas no se consideran peyorativas en el ámbito comunicativo de amistad juvenil. Por el contrario, los hablantes adultos las consideran insultantes o amenazantes de la imagen positiva del interlocutor. Para ilustrar este caso, se puede observar que el Diccionario de la Real Academia Española (RAE, 2014) recoge estas voces como insultantes. Por ejemplo, "perro, rra 2. m. y f. coloq. Persona despreciable. U. t. c. insulto"; "estúpido, da 1. adj. Necio, falto de inteligencia. U. t. c. s.", "marica 3. adj. despect. malson. Dicho de un hombre: homosexual. U. m. c. s. m. U. t. c. insulto". Como se observa en las acepciones previas, estas voces tienen un significado de insulto. Sin embargo, los jóvenes han resignificado estos términos asignándoles nuevos significados. Este procedimiento semántico se adelanta mediante la alteración de una palabra vieja, como señala UIImann (1972).

Desde los aspectos esbozados previamente, se afirma que los hablantes hacen uso de diversas FTN en el ámbito de amistad. Según lo recalca Fontanella (1999), las FTN obedecen a maneras genéricas de referirse a una misma realidad: "entre los jóvenes se muestra una variación amplísima casi sin puntos en común, lo que pone de manifiesto la existencia de relaciones en las que la variación en las fórmulas de tratamiento nominal es enor-

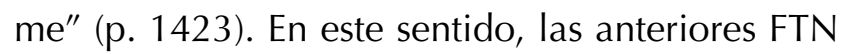
responden a diversas dinámicas de comunicación propias de los grupos juveniles con estrechos vínculos de diversa índole: amistad, compañerismo, prácticas culturales, sociales, deportivas e interacciones en redes sociales.

\section{El tratamiento nominal en el ámbito familiar}

El tratamiento nominal en el ámbito comunicativo familiar se clasifica en cuatro categorías junto con la frecuencia de uso, como se ilustra en la tabla 2. 
Tabla 2. El tratamiento nominal en el ámbito familiar

\begin{tabular}{lc}
\hline \multicolumn{1}{c}{$\begin{array}{c}\text { Fórmula de } \\
\text { tratamiento nominal }\end{array}$} & $\begin{array}{c}\text { Frecuencia } \\
\text { de uso } \mathbf{( \% )}\end{array}$ \\
\hline Nombre de pila & 40,09 \\
\hline Sobrenombre & 30,90 \\
\hline Fórmulas para padres y abuelos & 17,80 \\
\hline Fórmulas amor y mi vida & 11,20 \\
\hline
\end{tabular}

Fuente: elaboración propia.

\section{El nombre de pila}

La FTN más empleada por los jóvenes en sus interacciones familiares es el nombre de pila, con una frecuencia de $40,09 \%$. Por medio de esta el joven establece contacto con sus parientes más cercanos: hermanos, primos, abuelos y la pareja. En la familia, quienes reciben este tratamiento con una frecuencia alta son los primos y los hermanos. Los informantes declaran: "a todos los miembros de mi familia los llamo por el nombre" (informante 1, 13 años, mujer); "por lo general los Ilamo por el nombre" (informante 6, 17 años, mujer); "solo por el nombre" (informante 8, 16 años, hombre); "uso el nombre con mis familiares" (informante 12, 14 años, hombre). De manera similar, el estudio sociolingüístico realizado por Pedroviejo (2006) se resalta que "el nombre es el tratamiento preferido por ellos y ellas" -jóvenes- para con los familiares. Lo anterior es confirmado por Álvarez (2005), quien señala que "en el trato entre familiares se suele utilizar el nombre del interlocutor" (p. 38). No obstante, el nombre de pila no se manifiesta con los abuelos. En este caso concreto, se irrumpe la tendencia juvenil de usar el nombre de pila para denominar a los adultos mayores en la familia.

Se resalta el nombre de pila empleado en las interacciones comunicativas con la pareja. Su uso denota cercanía y confianza. Se destaca porque indica una relación simétrica entre la pareja. La información suministrada por los hablantes evidencia que "con mi novio nos llamamos por el nombre varias veces" (informante 14, 13 años, mujer); "normalmente Ilamo a mi novia por su nombre" (informante 18, 14 años, hombre); "mis parejas me dicen regularmente por el nombre" (informante 50, 16 años, mujer). Sin embargo, se evidencia en las grabaciones espontáneas que esta puede variar según la entonación. Se señala que la enunciación de esta fórmula con la pareja es tendencia en el ámbito hispánico de acuerdo con los hallazgos de Pedroviejo (2006): "los chicos lo emplean en un alto porcentaje el nombre y las chicas también" para referirse a la pareja; y Castellano (2008) afirma que "entre los jóvenes de Medellín [...] el nombre propio como tratamiento en la pareja representa uno de los porcentajes más altos" (p. 178). Los resultados de los estudios previos indican que el empleo del nombre de pila con la pareja es una tendencia generalizada en las comunidades hispánicas juveniles.

\section{La fórmula sobrenombre con valor de cercanía entre los hablantes}

Los jóvenes emplean sobrenombres para referirse a sus parientes más cercanos, como: primos, hermanos y abuelos; esta fórmula presenta una frecuencia de 30,90 \%. Según lo manifestado por los informantes: "con mis familiares de confianza les tengo apodos" (informante 12, 14 años hombres); "me dirijo a mis primos con apodos" (informante 14, 13 años, mujer); "especialmente a mis abuelitos les digo apodos" (informante 53, 17 años, hombre); "con todos mis hermanos nos denominados con apodos" (informante 64, 16 años, mujer). En la norma estándar social, un apodo suele ser por excelencia una amenaza a la imagen positiva del interlocutor y resulta ser ofensivo. No obstante, esta tendencia pierde validez porque los sujetos objeto de estudio atribuyen un uso diferente al configurado por el adulto. De modo que el empleo de apodos en el habla cotidiana juvenil en el interior de la familia se constituye como parte de la expresión del comportamiento lingüístico del joven y, a su vez, estos son resignificados en una forma de tratamiento con una connotación positiva. 
Así mismo, el apodo se constituye en una FTN que satisface una serie de intereses sociales y lingüísticos de las comunidades de habla juveniles de apartarse de la norma o de la conducta lingüística del adulto. De esta manera, los sobrenombres facilitan la creación de un sistema de disposiciones lingüísticas que le permiten satisfacer ese propósito (Catalá, 2002). La configuración de los apodos como deíctico social da cuenta de la transformación que los individuos en su discurso logran darle a su habla en comparación con el lenguaje del adulto. De modo que no se trata de imponer una moda o que obedezca a un aspecto pasajero. Por el contrario, la resemantización de los seudónimos demuestra la capacidad creadora del joven para cambiar la realidad y percepción del mundo a través de su habla.

En este sentido, el joven se aleja de la conducta lingüística estándar de la comunidad de habla -la del adulto- para establecer una propia; se realiza en principio mediante la resemantización del apodo con el propósito de percibir su contexto desde otra perspectiva -diferente a la del adulto-. La asignación de nuevos significados a los sobrenombres no es producto de la rebeldía o moda, sino porque el joven observa que las condiciones socioculturales en donde se ubica son totalmente diferentes. Por ende, se necesitan nuevos ítems léxicos para la interpretación de las actuales situaciones socioculturales. La resemantización es una conducta lingüística por parte del joven que se convierte en una práctica lingüística que cohesiona al grupo.

\section{Fórmulas para denominar a los padres y abuelos}

A continuación, se relacionan las FTN para interactuar con los padres y los abuelos con una frecuencia del 9,79\%. Entre ellas se encuentran papá, mamá, ma y pa (apócope de papá y mamá), madre, padre, mami, papi. De acuerdo con los hablantes: "a mis padres me dirijo como papá y mamá. Otras veces como pa o ma" (informante 66, 15 años, hombre); "casi siempre los Ilamo por papá y mamá, o papi y mami" (informante
69, 16 años, mujer); "a mis papás como madre y padre" (informante 42, 17 años, hombre). Las cuatro primeras son formas tradicionales en el ámbito hispánico, las cuales están vigentes en los jóvenes como vocativos de tratamiento para indicar relaciones de parentesco. La frecuencia de uso indica que estas fórmulas aún tienen una amplia aceptación en el contexto comunicativo familiar. Estos deícticos sociales están ampliamente empleados en el español general tanto peninsular como continental.

De manera similar, las fórmulas abuelito-a y abuelo-a son tratamientos establecidos con una frecuencia de uso del 8,01\% como maneras tradicionales para denominar a los abuelos por parte de los jóvenes. Para los informantes, ambas formas son comunes en la comunicación cotidiana: "a mis abuelos algunas veces les digo abuelo o abuela [...]. Aunque prefiero abuelito o abuelita" (informante 39, 17 años, mujer); "les digo abuelo o abuela. También, uso abuelito o abuelita" (informante 34, 15 años, hombre). Esta última se mantiene en el ámbito de las interacciones familiares como una manera canónica de contactar con los abuelos. Sin embargo, la fórmula abuelito-a tiene mayor predilección de uso de acuerdo con la comunidad de habla objeto de estudio para denominar a los abuelos. En una investigación realizada por Molina (2002) y García (2014), se encontró esta misma tendencia en las comunidades tanto del español peninsular como del español colombiano.

\section{Las fórmulas amor y mi vida en el interior de la familia}

Los tratamientos amor y mi vida se enuncian en la comunicación cotidiana juvenil en el interior de la familia con una frecuencia del 11,20\%. Estas dos presentan una significación de respeto y cercanía en el intercambio comunicativo juvenil en el seno de la familia. En este sentido, los informantes declaran: "les digo amor a mis hermanas o primas" (informante 52, 15 años, hombre); "algunas veces utilizo mi vida y amor con mi familia" (informante 
69, 17 años, mujer); "empleo amor y mi vida con mi familia" (informante 58, 16 años, hombre). La primera de ellas se emplea como una forma de cortesía positiva, mas no implica necesariamente una relación estrecha o de cercanía entre interlocutores. Lo anterior es confirmado por Carricaburo (1997): "en algunos casos la efectividad no existe y son simples fórmulas más o menos cordiales de iniciar un contacto lingüístico" (p. 50). De hecho, su uso se extiende a otros ámbitos comunicacionales donde la afectividad no se involucra. La segunda, se utiliza como tratamiento que denota mayor cercanía y efectividad en contraste con amor.

En este contexto particular, se recurre a diversas fórmulas nominales para el tratamiento con los padres y abuelos, con un bajo uso: viejito-a, tata, cucho-a, mita, pito, ma, mamita, apá y amá; con los hermanos y los primos: niño feo, bruja, parce, chino-a, lámpara; con la pareja: beibi, parcerito-a, musa, cosito-a, papaito, rey, reina, flaco-a. Estas FTN están asociadas con la manera como los jóvenes determinan sus relaciones sociales en sus comunicaciones cotidianas. En otras palabras, el joven enuncia estas fórmulas para cambiar la relación asimétrica por una simétrica con los miembros de su familia y pareja. Sin embargo, su uso está restringido por valores socioafectivos y los vínculos establecidos entre los interlocutores. En este sentido, el ámbito familiar desempeña un papel fundamental porque sitúa a los hablantes en un contexto particular con unas características específicas, como la cercanía, el grado de confianza y los roles establecidos entre parientes, aspectos que son conocidos previamente por los interlocutores.

Desde el contexto anterior, la utilización del tratamiento nominal en las interacciones comunicativas juveniles se comprende en el marco de norma social propia de los jóvenes y que son comprendidas por sus parientes cercanos. Según afirma Molina (2002), "el uso de una u otra alternativa, por lo tanto, es el resultado de la elección consciente del hablante y cualquier innovación tiene que producirse también en el nivel de consciencia" (p. 99). Así pues, las FTN empleadas en el contexto familiar se inscriben en una elección autónoma del sujeto, la cual es aceptada por los demás miembros de su núcleo familiar. De lo contrario, dichas FTN perderían validez y los jóvenes tendrían a recurrir a las formas nominales tradicionales.

\section{El tratamiento nominal en el ámbito social}

En la tabla 3, se ilustran los tratamientos agrupados en tres denominaciones y se señala la frecuencia de uso de las fórmulas presentes en el ámbito social.

Tabla 3. El tratamiento nominal en el ámbito social

\begin{tabular}{lc}
\hline $\begin{array}{c}\text { Fórmula de tratamiento } \\
\text { nominal }\end{array}$ & $\begin{array}{c}\text { Frecuencia } \\
\text { de uso }(\%)\end{array}$ \\
\hline El nombre de pila & 52,60 \\
\hline Fórmulas para los docentes & 32,70 \\
\hline Fórmulas para los médicos & 14,70 \\
\hline
\end{tabular}

Fuente: elaboración propia.

\section{El nombre de pila}

El nombre de pila es la FTN más usada por los jóvenes en el ámbito social frente a los siguientes interlocutores: desconocidos, empleados de servicios generales, vecinos y profesores, con un porcentaje de $52,60 \%$. El anterior tratamiento es frecuente para indicar la distancia social. Aun así, los hablantes tienden a disminuir el uso de este deíctico social de acuerdo con el nivel de interacción con sus interlocutores. En las situaciones comunicativas predominan los tratamientos: [veci - vecino-a + nombre], [señor, señora + nombre], [don, doña + nombre]. Ante estas elecciones, los informantes declaran: "a los vecinos les digo veci o vecino, junto con el nombre [...]; a las señoras del aseo por el nombre o señora más el nombre" (informante 54, 15 años, hombre); "por el nombre, cuando 
me lo sé" (informante 24, 16 años, hombre); "con la gente que no me hablo constantemente por el nombre" (informante 28, 15 años, mujer). Las anteriores afirmaciones evidencian que los interlocutores poseen un grado intermedio de confianza. Desde el contexto previo, se puede afirmar que el nombre de pila se convierte en la FTN enunciada por excelencia en los jóvenes para sus interlocutores con quienes se posee una distancia social o un grado relativo de confianza.

Asimismo, el nombre de pila se emplea como vocativo de tratamiento para referirse a los docentes. Se evidencia que los jóvenes denominan a sus maestros por el nombre en todas las situaciones" (informante 64, 16 años, mujer); "casi siempre los llamo por el nombre" (informante 66, 15 años, hombre); "a mis profes los llamo por su nombre" (informante 36, 15 años, hombre). Este hecho llama la atención porque pone en evidencia que existe una tendencia a disminuir el uso de títulos honoríficos como señorita, señor, maestro-a, profesor-a. Se observa, entonces, la ruptura de la relación asimétrica entre educando y docente cuando no se establece el uso de títulos honoríficos. De manera similar, se presentan las formas [profesor-a + nombre] y prof, profe, [profe + nombre]. La primera es tradicional en el habla hispana para establecer contacto con el docente; mientras que las segundas no son consideradas canónicas dentro de las comunidades hispánicas, tratamientos que son apócopes de la forma estándar profesor-a. Según afirma Montes et al. (1998), el tratamiento profe tiene un "registro de alto predominio entre los jóvenes y en el nivel de secundaria" (p. 141). Por ello, se sostiene que esta fórmula ha mantenido su uso entre los jóvenes bogotanos encuestados en los niveles de educación básica secundaria y media vocacional.

De manera similar, el nombre de pila es el deíctico social para referirse a los vecinos, este tiene mayor uso respecto de otros vocativos de tratamiento. En este contexto, se puede afirmar que el predominio del nombre corresponde con la fórmula más destacada para denominar a los vecinos, como señalan los informantes: "Siempre llamo a mis vecinos por su nombre" (informante 3, 16 años, hombre); "a los vecinos por su nombre" (informante 7, 17 años, mujer); "la mayoría de veces por el nombre" (informante 56, 14 años, hombre); "los vecinos se tratan por el nombre" (informante 62, 15 años, hombres). Sin embargo, los jóvenes emplean otras formas para establecer contacto con las personas que residen en su mismo lugar, estas son: señor, señora, [señor-a + nombre], don, doña. La distancia social entre joven y adulto establecida en algunas situaciones, en el ámbito social, propicia la utilización de las formas previamente mencionadas. Estos tratamientos se inscriben dentro del ámbito de la tradición hispánica para denominar a los vecinos.

\section{Las fórmulas miss y teacher para referirse a los docentes}

Para establecer contacto con los docentes, se presentan las fórmulas miss, teacher, [miss + nombre], [teacher + nombre] con un índice de frecuencia de $32,70 \%$. Al respecto, los informantes sostienen: "a todos mis profes les digo por miss o teacher" (informante 63, 13 años, hombre); "por lo general uso teacher más el nombre" (informante 25, 14 años, mujer); "les digo teacher o miss" (informante 30, 15 años, mujer). Estos tratamientos se han tomado como préstamos léxicos del inglés. La influencia de este idioma, el cual es una lengua franca, ha sido la causa de la adopción de esta forma nominal. En el contexto bogotano, el vocativo de tratamiento teacher se registró en el estudio realizado por Montes et al. (1998). Sin embargo, existe una diferencia de uso porque "teacher: presenta exclusión total entre las mujeres" (Montes et al., 1998, p. 141). El hallazgo de esta investigación revela que en la actualidad el uso de este tratamiento se establece sin distinción de sexo. Por ello, se asegura que la utilización cambió en cuanto al sexo de los interlocutores. 


\section{Las fórmulas para referirse a los médicos}

Las formas nominales utilizadas por los jóvenes para referirse al médico son doc (apócope de doctor), doctor-a, [doctor-a + nombre]; estas representan el $14,70 \%$ de la frecuencia de uso. De acuerdo con las voces de los jóvenes informantes: "doctor, porque no me sé el nombre ni lo conozco" (informante 22, 13 años, hombre); "suelo usar doc (sic) o doctor" (informante 26, 17 años, mujer); "uso doctor o doctora y el nombre si lo sé" (informante 57, 16 años, hombre); "utilizo el nombre o doctor" (informante 9, 16 años, mujer). Estas FTN obedecen a las maneras tradiciones en las comunidades lingüísticas hispánicas como deícticos sociales para establecer contacto con el profesional de la salud. Por ende, no se encuentran nuevas formas para denominar al médico. Se observa que las FTN se mantienen invariables para denominar a los galenos en relación con las usadas por los adultos.

En este ámbito comunicativo, la escuela desempeña un papel fundamental en las elecciones del tratamiento nominal por parte de los jóvenes. Se observa que en algunos contextos comunicativos escolares se ejerce una vigilancia del comportamiento comunicativo, puesto que los hablantes jóvenes deben responder a unas pautas interactivas propias de las instituciones educativas. En este aspecto, los informantes aseveran: "en mi colegio nos corresponde llamar a los profesores como miss o teacher y su nombre" (informante 25, 14 años, mujer); "es casi obligatorio llamar a los maestros como profesor o profesora" (informante 54, 15 años, hombre); "nos regañan si llamamos a los profes por su nombre" (informante 20, 16 años, hombre). El corpus permite confirmar que existe una predilección por los títulos honoríficos hacia los maestros en algunos centros educativos y, en estas instituciones, se hace énfasis particular en las buenas maneras para el trato del joven hacia los docentes en su interacción cotidiana. Incluso, se les ordena emplear las fórmulas inglesas miss o teacher, consideradas las más pertinentes para denominar a los docentes.

\section{Discusión}

El tratamiento es un mecanismo impulsado por un complejo engranaje que se manifiesta a través de construcciones lingüísticas específicas de cada comunidad de habla (Gutiérrez-Rivas, 2016). Para el caso del tratamiento establecido desde las FTN, este se construye según los intereses comunicativos de los hablantes involucrados en el intercambio comunicativo. El tratamiento consolida relaciones de poder, distancia social, intimidad, deferencia, la cortesía, lo cual se observa en los procesos léxicos adelantados al interior de los grupos sociales juveniles en la alternancia léxica y resemantización de algunas palabras para referirse a la segunda persona. Estos dos mecanismos dan cuenta de las estrategias sociopragmáticas Ilevadas a cabo por los jóvenes en sus apelaciones al interlocutor. El uso establecido por los emisores en el tratamiento nominal obedece a un principio de estrategia conversacional de corte léxico-semántico en sus discursos diarios al interior de una comunidad de habla.

El tratamiento nominal en el habla juvenil se establece como parte de su norma social y lingüística de los grupos, este se configura desde los diversos ítems léxicos empleados. Por ende, existe una diferencia en el tratamiento establecido por el grupo juvenil en relación con otros grupos etarios, los cuales recurren a los tratamientos canónicos propios de la norma estándar del español. En consecuencia, el comportamiento lingüístico juvenil es propio de este grupo etario, si se compara con otras comunidades de habla. La conducta lingüística determinada por el tratamiento nominal se convierte en una actitud de pertenencia generacional. De modo que los deícticos sociales empleados como FTN constituyen una expresión e identidad juvenil dentro de los distintos ámbitos comunicativos del joven, los cuales están determinados por aspectos sociales, culturales e intencionalidad comunicativa. Esto se puede comprender desde la afirmación 
de Catalá (2002): "la juventud ha conquistado un protagonismo que no tenía en épocas anteriores y se ha individualizado como clase social frente al mundo de los adultos" (p. 128).

En consonancia con lo anterior, se observa que las nuevas generaciones han adaptado o configurado un determinado léxico con el propósito de ser empleado como parte del tratamiento nominal. Se reafirma la idea que sostiene que se "puede observar que la nueva generación habla el idioma de una forma un tanto diferente que la anterior" (Pallares, 1976, p. 17). El tratamiento nominal se caracteriza por ser de inventario abierto, aspecto que se observa en las fórmulas empleadas por los jóvenes. Se evidencia un cambio de los términos empleados por parte de los jóvenes como fórmulas nominales en relación con otros grupos etarios. Aunque se mantiene el tratamiento estandarizado en especial en el ámbito familiar -abuelo-a, papá, mamá, padre, madre- y social -señor-a, señorita, profesor-a, don, doña, doctor-a-. Este fenómeno ocurre dado que una lengua es un estado que está regido por unas leyes fijas y, a su vez, la modificación está presente, ambas, pertenecen a la esencia íntima de la lengua (Pallares, 1976).

Las modificaciones en el tratamiento que emergen en los contextos de habla juvenil estudiados se insertan dentro de la variedad léxica propia de los cambios generacionales, de la nueva conceptualización social, estilo de vida y recientes perspectivas en la configuración de relaciones de poder entre interlocutores. Según Pallares (1976), los cambios lingüísticos se establecen porque "en realidad, cada lengua está sujeta a modificación y necesariamente tiene que estarlo para que pueda adaptarse a nuevas situaciones, nuevos estados de la sociedad, nuevas concepciones de la vida, nuevas personas" (p. 18). La variedad léxica en el tratamiento nominal se adapta a las situaciones emergentes donde se involucran los jóvenes. De ahí que se presentan algunas variaciones en las fórmulas destinadas al tratamiento entre amigos, familiares y demás interlocutores.
Ahora bien, dentro del tratamiento nominal las variables extralingüísticas desempeñan un papel determinante, pues estas contribuyen a dinamizar los aspectos para la variación lingüística en el tratamiento nominal. La edad es fundamental en la construcción de las variedades léxicas, ya que esta le atribuye al individuo determinadas licencias establecidas por el contexto comunicativo para emplear fórmulas específicas según la intención de interacción con los interlocutores. Así pues, en la comunicación juvenil como se ha venido insistiendo "se observa que determinadas elecciones lingüísticas realizadas por el hablante indican la relación social percibida entre los individuos" (Wardhaugh, 2006, p. 260). Se confirma que la utilización de diversos ítems léxicos en el tratamiento nominal es propio de las comunicaciones informales o semiformales de los jóvenes; aspecto que no está configurado en las interacciones formales. Para Danesi (2004), las estructuras gramaticales y léxicas cambian dependiendo del estado social de los hablantes, la edad, la intención de cada hablante y el objetivo de la conversación.

En la variable social sexo no se logra distinguir de manera delimitada un uso exclusivo de tratamientos propios de los hombres o las mujeres en el marco de los acontecimientos comunicativos registrados en el corpus. Las siguientes fórmulas nominales se emplean para denominar tanto a hombres como a las mujeres: amor, bebé, marica, beibi, mi vida, cielo, veci, prof, profe, doc, weon, güevón, morsh (sic), nene, cariño, panas, oso, muchachos, compañeros, mor, tesoro, parce. Se comprende que dentro de la comunicación juvenil la variable social sexo no ejerce un papel determinante en la elección de la FTN. Desde este hecho, no se puede corroborar la hipótesis donde se indica que los hombres introducen expresiones nuevas o contribuyen a la variación estilística y, por esto, renuevan el idioma (Jespersen, 2019), mientras que el habla de las mujeres es más conservadora (Moreno, 1998). Lo anterior se afirma porque en las conversiones espontáneas tanto hombre como mujeres 
emplearon formas del habla estándar y otras fórmulas -propias del grupo- sin distinción alguna.

El presente estudio evidenció que las FTN son funcionales en las interacciones comunicativas dado que la red social de los jóvenes objeto de estudio son cerradas con una alta densidad. Este aspecto se establece por diversos factores, como asistencia a la misma escuela; residencia en el mismo conjunto de apartamentos o barrio; participación en prácticas deportivas, de ocio o culturales en conjunto; uso de plataformas digitales y sociales de comunicación. Este compartir se deriva en la creación de lazos fuertes en el interior de los grupos juveniles. De ahí que los indicadores sociales como amistad, vecindad, escolaridad, interacción en la Web, prácticas deportivas o culturales determinan la alta densidad de la red social juvenil. Las situaciones anteriores están permeadas por la variable extralingüística edad. Esta contribuye a que los miembros del grupo juvenil tengan dichos indicadores sociales. El mismo principio fue encontrado por otros estudios; por ejemplo, para Coates (2009) "las redes sociales son más cerradas cuando sus miembros tienen alrededor de 16 años" (p. 128), y según García (1999), "entre los tres y catorce años se acentúa la influencia del grupo de pares y que, por lo tanto, psicológicamente se tienden a subrayar la cohesión grupal y a establecer fronteras generacionales" (p. 188).

A partir de lo anterior, se puede observar que el tratamiento nominal juvenil, desde el grupo estudiado, presenta una homogenización de los vocativos de tratamiento utilizados en las conversaciones de carácter formal e informal. La constitución unificada del grupo juvenil hace que las fórmulas tiendan a ser empleadas con un mismo interés comunicativo. El uso de las fórmulas nominales se convierte en una constante de unidad entre los jóvenes, pues estas son empleadas en primer lugar con miembros pertenecientes a la misma red social. De ahí que los hablantes con edades entre 15 a 17 años tiendan a liderar los procesos de unificación de las formas y, al mismo tiempo, cohesionan a los hablantes desde los acontecimientos comunicativos al interior del grupo. Los jóvenes con edades entre 13 y 14 años son imitadores del comportamiento lingüísticos de los sujetos que dirigen los acontecimientos comunicativos con un rango de edad entre 15 y 17 años.

La variación estilística establecida en el tratamiento nominal juvenil demuestra que las FTN están adaptadas a la conducta social del grupo estudiado en el marco de sus acontecimientos comunicativos. La variación estilística de las fórmulas nominales obedece a las características del comportamiento lingüístico juvenil, la cuales se pueden clasificar como una variación de uso para abordar aspectos comunicativos determinados, utilizados con un propósito casi homogéneo. En efecto, la elección de una fórmula canónica o no canónica está mediada por los componentes del contexto situacional, la relación entre los hablantes y el tipo de habla -formal, informal, vernácula-. Así pues, el contexto situacional configura el uso del tratamiento nominal juvenil desde sus componentes básicos de la interacción lingüística: el ámbito de uso, la intencionalidad comunicativa y los participantes.

Asimismo, se observa que la formación recibida por parte de los jóvenes en la escuela determina la elección de algunas fórmulas canónicas, a saber: el nombre de pila, profesor-a, vecino-a, señor-a, don, doña, doctor, madre, padre, mamá, papá. El papel regulador de la escuela desde la formación en vocativos de tratamientos estandarizados para referirse a los mayores, a las autoridades, a los docentes, a los padres y abuelos hace que los jóvenes empleen vocativos de tratamiento ajustados a la norma culta de los hablantes adultos. En la realidad del aula, el joven tiene que regular su discurso porque se encuentra constantemente en evaluación de sus actos de habla y si se desvía de la norma estándar es penalizado por sus maestros. Este hecho concreto incide de manera directa en las elecciones de los tratamientos para padres, maestros, médicos y personas desconocidas desde 
una fórmula de la lengua estándar de su comunidad de habla por parte de los hablantes jóvenes.

\section{Conclusiones}

Desde el entorno de amistad, las FTN empleadas por los jóvenes en sus situaciones comunicativas convergen en una estrategia conversacional, la cual manifiesta una solidaridad positiva para los miembros del grupo. Las FTN son enunciadas desde una codificación de cercanía, respecto y solidaridad de los interlocutores. Así pues, el tratamiento nominal se distingue por el grado de empatía con el interlocutor, aunque estas fórmulas poseen una carga semántica diferencial según la cercanía y el afecto entre los interlocutores que participan en la interacción dialógica.

El tratamiento nominal empleado por los jóvenes en sus situaciones comunicativas desde el ámbito familiar concuerda con las formas tradiciones de referencia a los parientes cercanos en las comunidades hispánicas del español peninsular como del continental: nombre de pila, abuelo-a, papá, mamá, padre, madre. En este contexto, se resaltan los sobrenombres como FTN, estos no transgreden la norma lingüística de los grupos discursivos estudiados. No obstante, los apodos resultan ser ofensivos para los hablantes adultos, que no están familiarizado con el tratamiento nominal juvenil.

Los tratamientos nominales empleados en el ámbito comunicativo social convergen en las relaciones donde el joven está subordinado al adulto, es decir, se presenta una relación asimétrica entre estos dos interlocutores. Este aspecto hace que predominen las formas canónicas utilizadas en la norma culta del contexto hispánico. Entre ellas están doctor-a, don, doña, maestro-a, nombre de pila, profesor-a, señor-a, señorita y vecino-a. Los jóvenes sostienen contacto con sus interlocutores adultos a partir de formas preestablecidas por su comunidad lingüística de manera prioritaria. No obstante, los hablantes jóvenes hacen una sustitución de las fórmulas estándares para utilizar aquellas derivadas de apócopes y préstamos léxicos de la lengua inglesa. En este sentido, los deícticos sociales miss, prof, profe y teacher están orientadas a establecer una relación simétrica con el docente. Este aspecto indica un cambio en la concepción de autoridad por parte del joven, ya que al profesor se trata con un determinado grado de confianza. Dicho fenómeno no sucedía en décadas previas, porque enunciar este tratamiento era considerado como una falta de respeto.

En las situaciones comunicativas juveniles, se resalta una gran variedad de ítems léxicos empleados como fórmulas nominales de tratamiento en los acontecimientos comunicativos. Las FTN son diversas y estas se insertan en los eventos comunicativos con una significación particular, que está codificada en la red social del grupo juvenil. Las fórmulas son un componente fundamental en la interacción dentro y fuera del grupo, tanto con jóvenes perteneciente a la comunidad juvenil como con familiares que comprenden algunas de las formas de tratamiento empleadas por estos. En ambas situaciones, se siguen unas reglas de uso definidas por los jóvenes y que son comprendidas por los adultos cuando se emplean fórmulas nominales en la interacción con adultos. De modo que parte del léxico empleado como tratamiento nominal juvenil se inserta en dos ámbitos concretos: el amistoso y el familiar. En contraste, en el contexto social se emplean fórmulas que no son parte de la creación juvenil.

Ante la diversidad de tratamientos nominales que se emplean en el habla juvenil en la comunicación formal e informal de jóvenes residentes en la localidad de Kennedy, es necesario ampliar la investigación a otros espacios de la ciudad de Bogotá D.C. Esto, debido a que se analiza el tratamiento nominal desde los intercambios comunicativos en tres ámbitos concretos, aspecto que no contempla otros contextos interactivos donde se hace presente el joven. Hay que mencionar, además que la muestra tuvo un carácter limitado. Por ende, se hace necesario un estudio más amplio con el propósito de corroborar y contrastar los tratamientos nominales presentados en este estudio. 


\section{Reconocimientos}

Este artículo presenta uno de los resultados de la investigación denominada "Las fórmulas tratamiento nominal en el habla de los jóvenes bogotanos", adelantado en la formación posgradual de la Maestría en Lingüística del Instituto Caro y Cuervo. Se agradece a los jóvenes que participaron de manera activa en el proyecto.

\section{Referencias bibliográficas}

Alba de Diego, V. y Sánchez, J. (1980). Tratamiento y juventud en la lengua hablada. Aspectos sociolingüísticos. Boletín de la Real Academia Española, 60(1), 95-130. Recuperado de https://dialnet.unirioja.es/servlet/articulo?codigo $=52377$

Álvarez, A. (2005). Hablar en español. La cortesía verbal. La pronunciación del español estándar. Las formas de expresión oral. Oviedo: Ediuno.

Álvarez, A. y Caraballo, E. (2016). Estudio sociolingüístico de los apelativos en el habla de los jóvenes de Cartagena de Indias. [Tesis de pregrado]. Universidad de Cartagena, Cartagena, Colombia.

Arias, F., García, M. y Ruiz, A. (2016). Fórmulas de tratamiento nominal en la Universidad de Antioquia. Aproximaciones al habla de estudiantes de las Facultades de Educación e Ingeniería. Cuadernos de Lingüística Hispánica, 27(1), 57-77. Recuperado de http://www.scielo.org.co/pdf/clin/n27/n27a04.pdf

Arrieta, L. y Avendaño, G. (2018). El discurso del tuit: un análisis lingüístico, sociodiscursivo y sociopragmático. Cuadernos de Lingüística Hispánica, 32(1), 107-130. DOI: 10.19053/0121053x. N32.2018.8123

Baker, P. (2010). Sociolinguistics and corpus linguistics. Edimburgo: Reino Unido: Edinburgh University Press.

Berenguer, J. (2001). Estrategias del discurso conversacional: algunos casos del relato coloquial en catalán y español. Tomo I. Montevideo: Editorial Universidad de San Juan.
Blas, J. (2004). Sociolingüística del español. Desarrollos y perspectivas en el estudio de la lengua española en contexto social. Madrid: Ediciones Cátedra.

Calsamiglia, H. y Tusón, A. (2015). Las cosas del decir. Manual de análisis del discurso. Barcelona: Ariel.

Carricaburo, N. (1997). Las formas de tratamiento en el español actual. Madrid: España: Arco Libros, S. L.

Castellano, M. (2008). Formas de tratamiento nominales para la pareja en el habla juvenil medellinense. Ílkala, Revista de Lenguaje y Cultura, 13(20), 163-181. Recuperado de https://www.redalyc.org/ pdf/2550/255020456006.pdf

Castellano, M. (2011). Caracterización morfológica de las fórmulas de tratamiento nominales en el habla de Medellín. Revista Virtual Universidad Católica del Norte, 32(1), 220-246. Recuperado de https:// revistavirtual.ucn.edu.co/index.php/RevistaUCN/ article/view/33/75

Castellano, M. (2012). Cortesía verbal y fórmulas de tratamiento nominales en el habla de Medellín. Lingüística y Literatura, 26(2), 123-139. Recuperado de https://revistas.uptc.edu.co/index.php/ linguistica_hispanica/article/view/464

Castellano, M. (2014). Estudio lexicológico de las formas de tratamiento nominales en el habla de Medellín. En Clave Social, 2(1), 17-28. Recuperado de http://repository.lasallista.edu.co:8080/ojs/index. php/EN-Clave/article/view/490

Castellano, M. (2017). Análisis pragmático de la función de los tratamientos nominales en actos de habla descorteses en Medellín (Colombia). Forma y Función, 30(2), 139-162. DOI: 10.15446/fyf. v30n2.65794

Catalá, N. (2002). Consideraciones acerca de la pobreza expresiva de los jóvenes. En F. Rodríguez (ed.), El lenguaje de los jóvenes (pp. 123-134). Barcelona: Editorial Ariel S. A.

Coates, J. (2009). Mujeres, hombres y lenguaje. Un acercamiento sociolingüístico a las diferencias de género. México: Fondo de Cultura Económica.

Danesi, M. (2004). A basic course in anthropological Linguistics. Toronto: Canadian Scholar's Press Inc. 
Escandell, M. (1995). Cortesía, formulas convencionales y estrategias. Revista Española de Lingüística, 25(1), 31-66. Recuperado de https://dialnet.unirioja.es/servlet/articulo? codigo $=41313$

Escandell, M. (2014). La comunicación: lengua, cognición y sociedad. Madrid: Ediciones Akal.

Fontanella, B. (1999). Sistemas pronominales de tratamiento usados en el mundo hispánico. En I. Bosque y V. Demonte (ed.), Gramática descriptiva de la lengua española (pp. 1399-1426). Madrid: Espasa Calpe S., A.

García, A. (2014). Las formas de tratamiento en el español colombiano. Recuperado de https://www. academia.edu/7394896/_Las_f\%C3\%B3rmulas_ de_tratamiento_en_el_espa\%C3\%B1ol_de_Colombia

García, F. (1999). Fundamentos críticos de sociolingüística. Almería: Ediciones Universidad de Almería.

Gómez, M. (2016). Análisis lingüístico y sociopragmático de las fórmulas de tratamiento nominal en el Senado colombiano. Rastros Rostros, 18(33), 11-26. DOI: 10.16925/ra.v18i33.1721

Gutiérrez-Rivas, C. (2016). La palabra marico como nueva forma de tratamiento nominal en el habla de los jóvenes universitarios de Caracas: un estudio desde la perspectiva de los hablantes. Logos, Revista de Lingüística, Filosofía y Literatura, 26(1), 3-22. DOI: 10.15443/RL2601

Halliday, M. A. (2017). El lenguaje como semiótica social. La interpretación social del lenguaje y del significado. México: Fondo de Cultura Económica.

Hernández, J. y Almeida, M. (2005). Metodología de la investigación sociolingüística. Madrid: Editorial Comares.

Jespersen, O. (2019). Language: its nature, development and origine. Londres: Good Press.

Medina, F. (2010). La metodología en los estudios sobre formas y fórmulas de tratamiento en español. En M. Hummel, B. Kluge y M. Vázquez (eds.), Formas y fórmulas de tratamiento en el mundo hispánico (pp. 21-56). México: El Colegio de México.
Medina, J. (1991). Formas de tratamiento en Canarias: habla juvenil. Santa Cruz de Tenerife: Producciones Gráficas S. A.

Mestre, M. (2011). Alternancia de pronombres en el habla de Bogotá. Enunciación, 17(2), 17- 30. DOI: 10.14483/22486798.3903

Miranda, Y. y Payares, A. (2018). Fórmulas de tratamiento en la radio de Cartagena: una aproximación sociopragmática. [Tesis de pregrado]. Universidad de Cartagena, Cartagena, Colombia.

Molina, I. (2002). Evolución de las fórmulas de tratamiento en la juventud madrileña a lo largo del siglo XX: un estudio en tiempo real. En F. Rodríguez (ed.), El lenguaje de los jóvenes (pp. 97-113). Barcelona: Editorial Ariel S., A.

Montero, P. (2011). Las formas nominales de tratamiento en el habla juvenil de Extremadura. Revista de Estudios Extremeños, 67(1), 47-68. Recuperado de https://dialnet.unirioja.es/servlet/ articulo? codigo $=3670686$

Montes, G., Figueroa, J., Mora, S., Lozano, M., Aparicio, R., Espejo, M. y Duarte, G. (1998). El español hablado en Bogotá. Análisis previo de su estratificación. Bogotá: Imprenta Patriótica Instituto Caro y Cuervo.

Moreno, F. (1998). Principios de sociolingüística y sociología del lenguaje. Barcelona: Editorial Ariel, S. A.

Pallares, B. (1976). Sistema lingüístico y cambio lingüístico. Madrid: Editorial Gredos.

Pedroviejo, J. (2006). Un estudio sociolingüístico. Sistemas de tratamiento de la juventud de Valladolid. Tono Digital, 11(1), 1-21. Recuperado de https:// www.um.es/tonosdigital/znum11/estudios/20-tratamiento.htm

Plazas, A. (2013). Caracterización léxica sobre el habla de los jóvenes. Folios de Humanidades y Pedagogía, 20(2), 62-73. Recuperado de https:// revistas.pedagogica.edu.co/index.php/FHP/article/ view/2091/2000

Real Academia Española (2014). Diccionario de le lengua española. Madrid: Espasa. 
Rebollo, L. (2005). Formas de tratamiento y cortesía en el mundo hispánico. Revista Instituto Cervantes, 7(1), 35-66. Recuperado de https://cvc.cervantes. es/ensenanza/biblioteca_ele/publicaciones_centros/PDF/rio_2005/03_rebollo.pdf

Rodríguez, F. (2002). El lenguaje de los jóvenes. BarceIona: Editorial Ariel.

Silva-Corvalán, C. (2001). Sociolingüística y pragmática del español. Washington: Georgetown University Press.

Terrádez, M. (2001). Frecuencias léxicas del español coloquial: análisis cuantitativo y cualitativo. Valencia: Universidad de Valencia.
Torres, D. (2017). Análisis sociolingüístico de las fórmulas de tratamiento empleadas por conductores y sparring de la ruta Olaya-Centro de Cartagena. [Tesis de pregrado]. Universidad de Cartagena, Cartagena: Colombia.

Ullmann, S. (1972). Semántica: introducción a la ciencia del significado. Madrid: Aguilar.

Wardhaugh. R. (2006). An introduction to sociolinguistics. Oxford: Blackwell Publishing.

\section{(c) (i) (5)}

